\title{
The Cannabinoid CB1 Receptor Mediates Retrograde Signals for Depolarization-Induced Suppression of Inhibition in Cerebellar Purkinje Cells
}

\author{
Takayuki Yoshida, ${ }^{1}$ Kouichi Hashimoto, ${ }^{1}$ Andreas Zimmer, ${ }^{2}$ Takashi Maejima, ${ }^{1}$ Kenji Araishi, ${ }^{1}$ and \\ Masanobu Kano' ${ }^{1}$ \\ 1Department of Cellular Neurophysiology, Graduate School of Medical Science, Kanazawa University, Kanazawa \\ 920-8640, Japan, and 2Department of Psychiatry, University of Bonn, 53105 Bonn, Germany
}

Action potential firing or depolarization of the postsynaptic neuron can induce a transient suppression of inhibitory synaptic inputs to the depolarized neuron in the cerebellum and hippocampus. This phenomenon, termed depolarizationinduced suppression of inhibition (DSI), is initiated postsynaptically by an elevation of intracellular $\mathrm{Ca}^{2+}$ concentration $\left(\left[\mathrm{Ca}^{2+}\right]_{\mathrm{i}}\right)$ and is expressed presynaptically as a suppression of the transmitter release. It is, therefore, thought that some retrograde signal must exist from the depolarized postsynaptic neurons to the presynaptic terminals. Recent studies on hippocampal neurons have revealed that endogenous cannabinoids (endocannabinoids) play a key role as a retrograde messenger. There are, however, conflicting reports that glutamate may be a candidate retrograde messenger for cerebellar DSI that acts on presynaptic group II metabotropic glutamate receptors (mGluRs). In this study, we examined whether endo- cannabinoids mediate retrograde signal for cerebellar DSI. We recorded IPSCs from Purkinje cells by stimulating putative basket cell axons in mouse cerebellar slices. DSI was readily induced in evoked IPSCs by a depolarizing pulse train. We found that DSI was completely occluded by a cannabinoid agonist, WIN55,212-2, was totally eliminated by a specific antagonist of the type 1 cannabinoid (CB1) receptor, SR141716A, and was deficient in the CB1 knock-out mouse. In contrast, a group II mGluR-specific agonist, $\left(2 S, 2^{\prime} R, 3^{\prime} R\right)-2-\left(2^{\prime}, 3^{\prime}\right.$-dicarboxycyclopropyl)glycine, did not completely occlude DSI, and an mGluR antagonist, $(R S)-\alpha$-methyl-4-carboxyphenylglycine, had no depressant effect on DSI. These results clearly indicate that the CB1 receptor mediates retrograde signal for DSI in cerebellar Purkinje cells.

Key words: inhibitory transmission; cerebellum; Purkinje cell; retrograde signal; synaptic modulation; cannabinoid receptor
The synapse is a main target of various neuromodulators in the CNS. In cerebellar Purkinje cells (Llano et al., 1991) and hippocampal neurons (Pitler and Alger, 1992; Ohno-Shosaku et al., 1998), action potential firing or postsynaptic depolarization causes a transient suppression of inhibitory synaptic inputs to the depolarized neuron. This phenomenon, termed depolarizationinduced suppression of inhibition (DSI), is initiated postsynaptically by an elevation of cytoplasmic $\mathrm{Ca}^{2+}$ concentration $\left(\left[\mathrm{Ca}^{2+}\right]_{\mathrm{i}}\right)$ and is expressed presynaptically as a suppression of the transmitter release (Llano et al., 1991; Pitler and Alger, 1992; Ohno-Shosaku et al., 1998), suggesting the existence of some retrograde messenger that mediates DSI. It is reported that glutamate is a candidate retrograde messenger of DSI in the cerebellum (Glitsch et al., 1996) and the hippocampus (Morishita et al., 1998). It is proposed that glutamate is released from the postsynaptic neuron in a $\mathrm{Ca}^{2+}$-dependent manner, acts on presynaptic metabotropic glutamate receptors (mGluRs) and suppresses GABA release. However, a widely used mGluR antagonist, $(R S)-\alpha$-methyl-4-carboxyphenylglycine (MCPG), is either

\footnotetext{
Received Aug. 29, 2001; revised Oct. 29, 2001; accepted Dec. 3, 2001.

This work was supported by Grants-in Aid for Scientific Research (K.H., M.K.) and by Special Coordination Funds for Promoting Science and Technology (K.H., M.K.) from the Ministry of Education, Science, Sports, Culture, and Technology of Japan. T.M. was a recipient of the Research Fellowships for Young Scientists from the Japan Society for the Promotion of Sciences.

Correspondence should be addressed to Masanobu Kano, Department of Cellular Neurophysiology, Graduate School of Medical Science, Kanazawa University, 13-1 Takara-machi, Kanazawa 920-8640, Japan. E-mail: mkano@med.kanazawa-u.ac.jp. Copyright (C) 2002 Society for Neuroscience $0270-6474 / 02 / 221690-08 \$ 15.00 / 0$
}

not effective in cerebellar Purkinje cells (Glitsch et al., 1996) or only partially effective in hippocampal neurons (Morishita et al., 1998) to antagonize DSI. It is therefore conceivable that glutamate may not be the major mediator, if any, for DSI.

Recent studies have provided strong evidence that endogenous cannabinoids (endocannabinoids) mediate retrograde signals for DSI in hippocampal neurons (Maejima et al., 2001a; Montgomery and Madison, 2001; Ohno-Shosaku et al., 2001; Wilson and Nicoll, 2001; Wilson et al., 2001). These studies indicate that endocannabinoids are released from depolarized hippocampal neurons in a $\mathrm{Ca}^{2+}$-dependent manner and act on cannabinoid receptors at inhibitory presynaptic terminals. In the cerebellum, a DSI-like phenomenon at excitatory synapses (depolarizationinduced suppression of excitation; DSE) is also mediated by endocannabinoids (Kreitzer and Regehr, 2001a; Maejima et al., 2001b). Cannabinoid receptors are the molecular targets for the active component $\Delta^{9}$-tetrahydrocannabinol of marijuana and hashish. They consist of type 1 (CB1) and type 2 (CB2) receptors (Matsuda et al., 1990; Munro et al., 1993) of which the CB1 is rich in various regions of the CNS (Herkenham et al., 1990, 1991). The CB1 receptors are strongly expressed at the basket cell terminals around Purkinje cell somata (Egertova and Elphick, 2000). Application of a cannabinoid agonist to cerebellar slices is shown to suppress spontaneous IPSCs in Purkinje cells (Takahashi and Linden, 2000). These results suggest that endocannabinoids mediate DSI of cerebellar Purkinje cells via CB1 receptors on inhibitory presynaptic terminals.

To test this hypothesis, we recorded IPSCs from mouse Pur- 
kinje cells by stimulating putative basket cell axons. We found that DSI was completely occluded by a cannabinoid agonist, WIN55,212-2, and was abolished by a specific CB1 receptor antagonist, SR141716A. Furthermore, DSI was deficient in Purkinje cells of the CB1 knock-out mouse. In contrast, a group II mGluR-specific agonist, $\left(2 S, 2^{\prime} R, 3^{\prime} R\right)-2-\left(2^{\prime}, 3^{\prime}\right.$-dicarboxycyclopropyl)glycine (DCG IV), did not completely occlude DSI and MCPG had no effect on DSI. These results clearly indicate that the retrograde signal for DSI is mediated by endocannabinoids in cerebellar Purkinje cells.

\section{MATERIALS AND METHODS}

Electrophysiological recording. All experiments were performed according to the guidelines laid down by the animal welfare committee of Kanazawa University. Parasagittal cerebellar slices (250- $\mu \mathrm{m}$-thick) were prepared from C57BL/6 mice aged 8-13 d postnatally, as described (Kano et al., 1995, 1997). Whole-cell recordings were made from visually identified Purkinje cells, using an upright microscope (BX50W I; Olympus, Tokyo, Japan). Resistance of the patch pipette was 3-6 M $\Omega$ when filled with the standard intracellular solution composed of (in $\mathrm{mM}$ ): 140 $\mathrm{CsCl}, 10 \mathrm{HEPES}, 1$ EGTA, $0.1 \mathrm{CaCl}_{2}, 4.6 \mathrm{MgCl}_{2}, 4 \mathrm{Na}-\mathrm{ATP}$, and 0.4 $\mathrm{Na}-\mathrm{GTP}, \mathrm{pH} 7.3$, adjusted with $\mathrm{CsOH}$. The pipette access resistance was compensated by $70-80 \%$. The composition of the standard bathing solution was (in mM): $125 \mathrm{NaCl}, 2.5 \mathrm{KCl}, 2 \mathrm{CaCl}_{2}, 1 \mathrm{MgSO}_{4}, 1.25$ $\mathrm{NaH}_{2} \mathrm{PO}_{4}, 26 \mathrm{NaHCO}_{3}$, and 20 glucose, which was bubbled continuously with a mixture of $95 \% \mathrm{O}_{2}$ and $5 \% \mathrm{CO}_{2}$. The bath solution was supplemented with $10 \mu \mathrm{M}$ 6-cyano-7-nitroquinoxaline-2,3-dione and $10 \mu \mathrm{M}$ $(R S)$-3-(2-carboxypiperazin-4-yl)-propyl-1-phosphonic acid for recording IPSCs. Membrane currents were recorded with an Axopatch-1D (Axon Instruments, Foster City, CA) amplifier. Glass pipettes filled with the standard extracellular solution were used to stimulate putative basket cell axons in the deep molecular layer close to the Purkinje cell layer. The PULSE software (HEKA Elektronik, Lambrecht/Pfalz, Germany) was used for stimulation and data acquisition. Two successive stimulus pulses with an interstimulus interval of $50 \mathrm{msec}$ were repeated every $3 \mathrm{sec}$. Purkinje cells were usually held at a membrane potential of -70 or -80 $\mathrm{mV}$. The signals were filtered at $3 \mathrm{kHz}$ and digitized at $20 \mathrm{kHz}$. The decay phase of IPSCs was fitted with a single exponential by using PULSE-FIT software (HEKA). In the end of each experiment, we applied $10 \mu \mathrm{M}$ bicuculline to the bath and confirmed that the recorded synaptic currents were $\mathrm{GABA}_{\mathrm{A}}$ receptor-mediated IPSCs. All agonists and antagonists (Tocris Cookson, Ballwin, MO, except SR141716A) were applied to the bath. For the perfusion of solutions containing WIN55,212-2, or SR141716A, different tubes were used to avoid contamination. SR 141716A was a generous gift from Sanofi Recherche.

Induction and estimation of DSI. To induce DSI, a series of depolarizing pulses ( 10 pulses of $100 \mathrm{msec}$ duration from -70 or $-80 \mathrm{mV}$ to 0 $\mathrm{mV}$, repeated at $1 \mathrm{~Hz}$ ) was applied to Purkinje cells. The depolarizing pulse train was applied repeatedly. However, the results from the first pulse train were excluded to minimize contamination with the rebound potentiation (Kano et al., 1992; Vincent et al., 1992). DSI was estimated as the percentage of the mean amplitude of five consecutive IPSCs after the pulse train (acquired between 3 and $18 \mathrm{sec}$ after the end of pulse) relative to that of five IPSCs just before the pulse train. The depression caused by drugs was estimated as the percentage of the mean amplitudes of 10 consecutive IPSCs during drug application relative to that before application. Averaged data from different experiments are presented as mean \pm SEM.

CB1 receptor knock-out mouse. CB1 receptor knock-out mice were generated as described (Zimmer et al., 1999). Briefly, the coding region of the CB1 gene was replaced between amino acids 32 and 448 with PGK-neo in embryonic stem cells. Chimeric mice derived from these cells were bred with C57BL/6J animals. Homozygous mutants (CB1-/-) and wild-type $(\mathrm{CB} 1+/+)$ mice were produced with heterozygous intermatings. In the present investigation, juvenile mutant mice with both sexes aged 9 and $12 \mathrm{~d}$ were used. Animals were housed in groups under standard laboratory conditions (12 hr light/dark cycle) with food and water available ad libitum.

$\mathrm{Ca}^{2+}$ imaging. Purkinje cells were loaded for at least $20 \mathrm{~min}$ with a $\mathrm{Ca}^{2+}$ indicator (Magnesium Green; Molecular Probes, Eugene, OR; 500 $\mu \mathrm{M})$ through patch pipette filled with the cesium-based intracellular solution that was composed of (in mM): $140 \mathrm{CsCl}, 10 \mathrm{HEPES}, 1$ EGTA, $0.1 \mathrm{CaCl}_{2}, 0.3 \mathrm{MgCl}_{2}, 4 \mathrm{Na}-\mathrm{ATP}$, and $0.4 \mathrm{Na}-\mathrm{GTP}, \mathrm{pH} 7.3$, adjusted with
$\mathrm{CsOH}$. Fluorescence images were acquired by using a high-speed confocal laser-scanning microscope (Oz; NOR AN Instruments Inc., Middleton, WI). The $\mathrm{Ca}^{2+}$-dependent fluorescence signals from selected regions of interest were background-corrected and expressed as increases in fluorescence divided by the prestimulus fluorescence values $\left(\Delta F / F_{0}\right)$ using Igor Pro software (Wavemetrics, Lake Oswego, OR).

\section{RESULTS}

\section{Depolarization-induced suppression of evoked IPSCs in mouse Purkinje cells}

Previous studies on DSI of cerebellar Purkinje cells were mostly performed on spontaneous IPSCs in the rat (Llano et al., 1991; Glitsch et al., 1996). We began by examining whether DSI can be induced for IPSCs evoked by stimulating putative basket cell axons in Purkinje cells of the mouse cerebellum. When a series of depolarizing pulses (10 pulses of $100 \mathrm{msec}$ duration from -70 to $0 \mathrm{mV}$, repeated at $1 \mathrm{~Hz}$ ) were applied to Purkinje cells, the subsequent IPSCs were suppressed transiently (Fig. 1A). We found that DSI can be induced repeatedly in the same Purkinje cell without any run-down of its magnitude (Fig. $1 A, D)$. DSI was accompanied by a clear change in the paired-pulse ratio (Fig. $1 B, C)$, confirming that DSI is caused by the decrease in GABA release from the inhibitory synaptic terminals. The average data from seven cells indicate that the suppression of IPSCs reached $26.2 \pm 8.1 \%$ of control immediately after the depolarizing pulse train and then recovered gradually within $60 \mathrm{sec}$ to the control level (Fig. 1E). These results indicate that DSI is readily induced for evoked IPSCs in mouse cerebellar slices by the depolarization pulse protocol similar to that used for spontaneous IPSCs in the rat.

\section{The group II metabotropic glutamate receptors are not involved in DSI}

Previous studies suggest that DSI is mediated by glutamate or glutamate-like substance, which is thought to be released from depolarized postsynaptic neurons, acts on presynaptic mGluRs and suppresses GABA release (Glitsch et al., 1996; Morishita et al., 1998; Glitsch and Jack, 2001). In cerebellar Purkinje cells, the group II mGluRs (mGluR2 and mGluR3) on inhibitory presynaptic fibers are reported to be responsible for DSI (Glitsch et al., 1996; Glitsch and Jack, 2001). We examined whether the DSI of evoked IPSCs in mouse Purkinje cells also involves the group II mGluRs. In the Purkinje cell shown in Figure $2 A$, bath application of a selective group II mGluR agonist, DCG IV $(0.3 \mu \mathrm{M})$, induced a reversible suppression of evoked IPSC amplitude to $67 \%$ of the control (Fig. $2 A c, A d$ ). DSI was not completely occluded by the DCG IV-induced suppression (Fig. 2Aa, $A b, A e, A f$ ). The level of the maximum suppression during DSI in the control (Fig. $2 A b$ ) was almost identical to that in the presence of DCG IV (Fig. 2Af). In the same Purkinje cell, bath application of MCPG (3 mM), a group I and II-specific mGluR antagonist, blocked the depressant effect of DCG IV on evoked IPSCs (Fig. $2 A g, A h$ ). In contrast, MCPG ( $3 \mathrm{~mm}$ ) had no effect on DSI (Fig. $2 A i, A j$ ). DCG IV clearly increased the paired-pulse ratio of evoked IPSCs (Fig. $2 B, C$ ), indicating that DCG IV caused reduction of GABA release presumably acting on mGluR $2 / 3$ at the inhibitory presynaptic fibers. The IPSC amplitude was depressed to $56.8 \pm 4.5 \%$ and $41.1 \pm 4.9 \%$ of control by DCG IV at 0.1 and $0.3 \mu \mathrm{M}$, respectively ( $n=5 ; p<0.05$; paired $t$ test). However, DCG IV at $3 \mu \mathrm{M}$ did not induce further depression $(36.7 \pm 6.1 \%$ of control) when compared with that at $0.3 \mu \mathrm{M}(n=5 ; p>0.05$; paired $t$-test), indicating that the depressant effect of DCG IV saturated at $0.3 \mu \mathrm{M}$. The summary graph in Figure $2 D$ shows that DSI was 

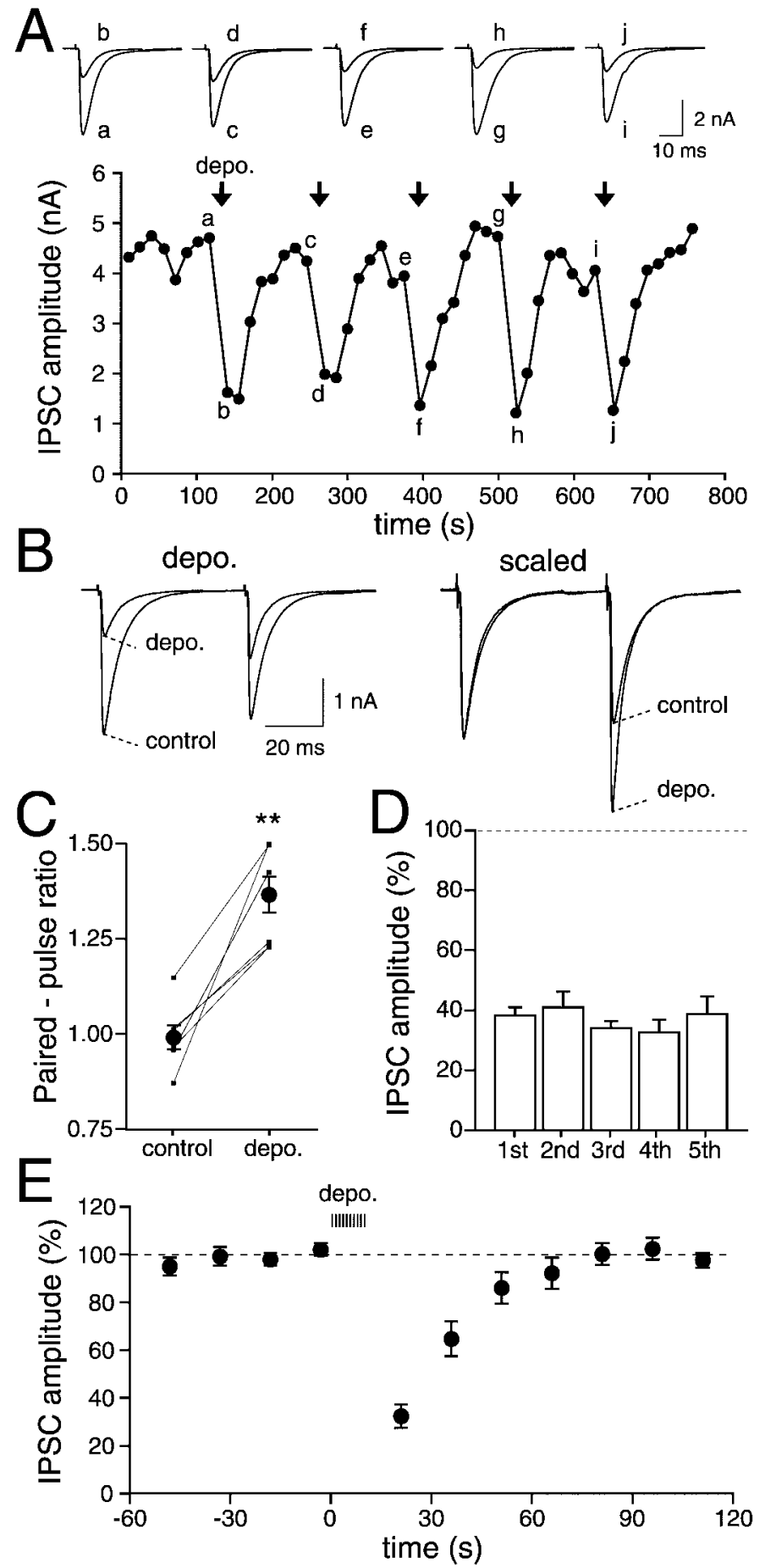

Figure 1. DSI of evoked IPSCs in mouse Purkinje cells. A, Top, Example of IPSC traces from a Purkinje cell by stimulating putative basket cell axons. Traces were acquired at the indicated time points in the graph of the bottom panel. Each trace is the average of five consecutive IPSCs. Bottom, Time course of the change in IPSC amplitudes. IPSCs were evoked at $0.33 \mathrm{~Hz}$. Each data point represents the mean of five consecutive IPSCs. Depolarizing pulse trains (10 pulses of $100 \mathrm{msec}$ duration from -70 to $0 \mathrm{mV}$, repeated at $1 \mathrm{~Hz}$ ) were applied to Purkinje cells at the time indicated by arrows. In the following figures, sample IPSC traces and the time course of the change in IPSC amplitudes from a representative Purkinje cell are illustrated in a similar manner as this figure. $B$, Example of IPSC traces (average of five consecutive responses) in response to paired stimuli (50 msec interval). Records obtained before (control) and after (depo.) the depolarizing pulse train are superimposed. In the right panel, the first IPSC after depolarization is scaled to the amplitude of the not occluded by DCG IV $(0.3 \mu \mathrm{M})$, and the effect of DCG IV $(0.3$ $\mu \mathrm{M})$ was effectively antagonized by MCPG (3 mM) (Fig. 2D). The summary data from six Purkinje cells show that neither the magnitude nor the time course of DSI was affected by MCPG (3 $\mathrm{mm}$ ) (Fig. 2E). These results clearly indicate that the group II mGluRs are not involved in DSI of evoked IPSCs in mouse Purkinje cells.

\section{CB1 receptors mediate DSI}

Recent studies clearly demonstrated that DSI in the hippocampus is mediated by endocannabinoids that are released from depolarized postsynaptic neurons and act retrogradely on presynaptic CB1 receptors (Ohno-Shosaku et al., 2001; Wilson and Nicoll, 2001; Wilson et al., 2001). We examined whether this scheme is also applied to the DSI in the mouse cerebellum. In the Purkinje cell shown in Figure $3 A$, bath application of a cannabinoid agonist, WIN55,212-2 (5 $\mu \mathrm{M})$, suppressed evoked IPSC amplitude to $32 \%$ of the control (Fig. $3 A c, A d$ ). DSI was completely occluded by WIN55,212-2 (Fig. 3Aa, $A b, A e, A f$ ). The effect of WIN55,212-2 was completely reversed by a selective $\mathrm{CB} 1$ receptor antagonist, SR141716A (1 $\mu \mathrm{M})$ (Fig. 3Ag, $A h)$. W IN55,212-2 clearly increased the paired-pulse ratio of evoked IPSCs (Fig. $3 B, C$ ), indicating that WIN55,212-2 caused reduction of GABA release acting on CB1 receptors at the inhibitory presynaptic fibers. The summary graph in Figure $3 D$ shows that DSI was completely occluded by WIN55,212-2, and the effect of WIN55,212-2 was totally antagonized by SR141716A $(1 \mu \mathrm{M})$. These data suggest that DSI and the WIN55,212-2-induced suppression share the common presynaptic mechanisms.

We then examined whether SR141716A can block DSI of evoked IPSCs in the mouse cerebellum. In the Purkinje cell shown in Figure $4 A$, the depolarizing pulse trains induced typical DSI of evoked IPSCs (Fig. $4 A a, A b, A c, A d$ ). Subsequent application of the same pulse trains after perfusion of SR141716A (1 $\mu \mathrm{M}$ )-containing external solution caused no change in IPSCs (Fig. $4 A e-A h)$. The summary data from six Purkinje cells clearly show that DSI was completely abolished by SR141716A (1 $\mu \mathrm{M})$ (Fig. 4B).

To confirm the involvement of CB1 receptors in DSI, we examined the cerebellum of the CB1 knock-out mouse. It is recently reported that hippocampal DSI is deficient in the CB1 knock-out mouse (Wilson et al., 2001). We found no perceptive difference in the kinetics and paired-pulse plasticity of IPSCs in Purkinje cells from the CB1 knock-out mouse. However, the depolarizing pulse train caused no change in the amplitude (Fig. $5 A, E$ ) or paired-pulse ratio (Fig. $5 B, C$ ) of IPSCs, indicating that DSI is totally deficient in the CB1 knock-out mouse. The group II mGluRs were functionally intact in the CB1 knock-out mouse because DCG IV caused a reversible inhibition of IPSCs that was very similar to that of the wild-type mouse (Fig. 5D,E). Further-

first IPSC of the control and superimposed. In the following figures, sample IPSC traces to paired stimuli from a representative Purkinje cell are illustrated in a similar manner as this figure. $C$, Changes in pairedpulse ratio induced by the depolarizing pulse train for individual Purkinje cells $(n=6)$. Data from the same Purkinje cells were connected. Closed symbols with error bars represent average values (mean \pm SEM). $D$, Reduction of IPSC amplitude induced by the depolarizing pulse trains applied at $120 \mathrm{sec}$ intervals to the same Purkinje cells $(n=4)$. E, Averaged time course of the changes in IPSC amplitudes induced by the depolarizing pulse train $(n=7)$. ${ }^{*} p<0.05 ;{ }^{*} p<0.01$ (paired $t$ test). 


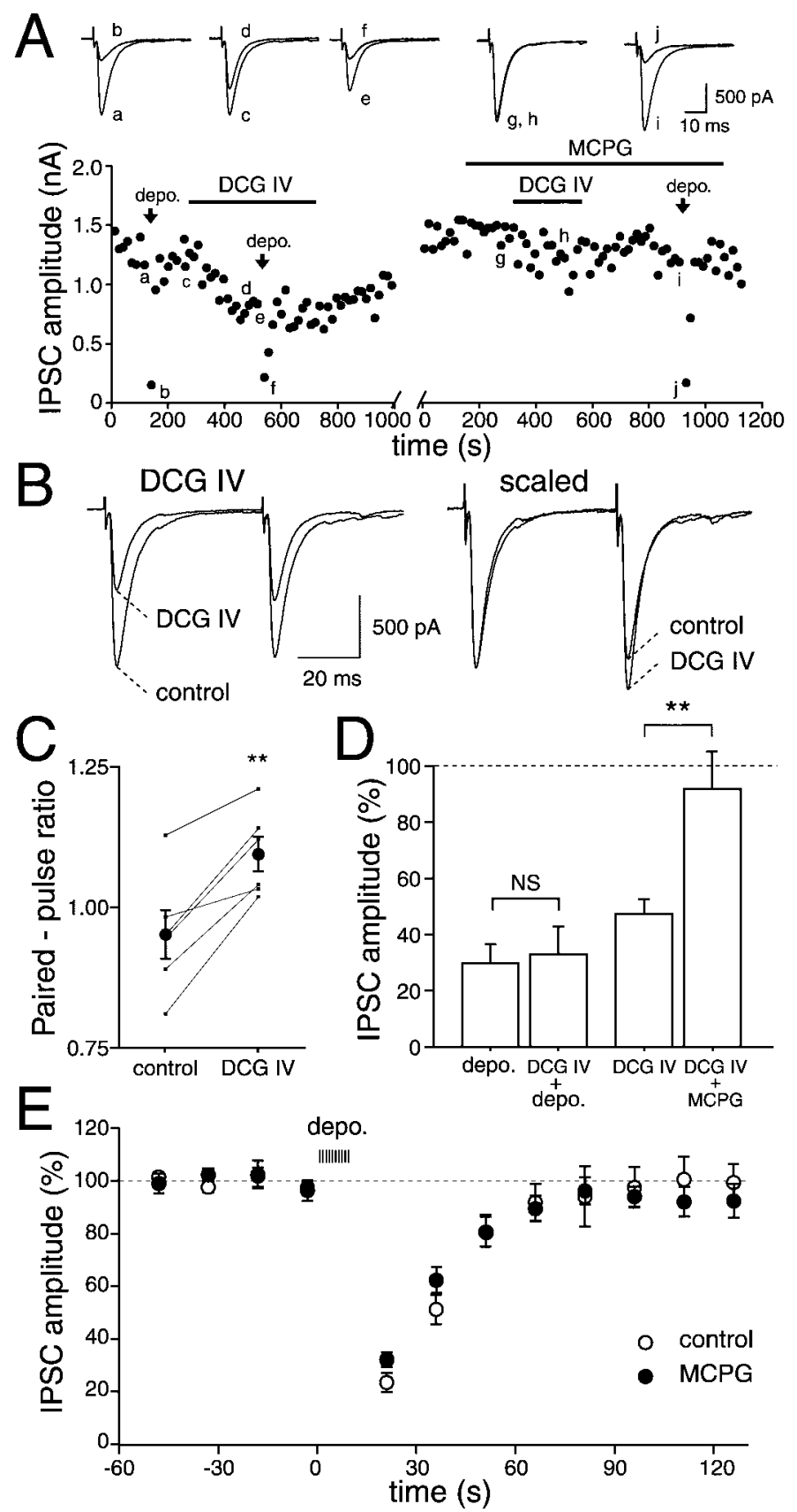

Figure 2. Group II mGluRs do not mediate DSI. $A$, Bath-applied DCG IV $(0.3 \mu \mathrm{M})$ induces a suppression of evoked IPSCs but the suppression does not completely occlude DSI. In the same Purkinje cell, the depressant effect of DCG IV on IPSCs is blocked by a group I and II-specific mGluR antagonist, MCPG (3 mM). In contrast, DSI is totally insensitive to MCPG (3 mM). B, Bath-applied DCG IV $(0.3 \mu \mathrm{M})$ induces a clear increase in the paired-pulse ratio of evoked IPSCs. $C$, Changes in pairedpulse ratio induced by DCG IV $(0.3 \mu \mathrm{M})$ for individual Purkinje cells $(n=$ 6 ; ${ }^{* *} p<0.01$; paired $t$ test). $D$, Summary bar graph for the changes in IPSC amplitudes induced by the depolarizing pulse train (depo.), the depolarizing pulse train plus $0.3 \mu \mathrm{M}$ DCG IV (DCG IV + depo.), $0.3 \mu \mathrm{M}$ DCG IV, and $0.3 \mu \mathrm{M}$ DCG IV in the presence of $3 \mathrm{~mm} \mathrm{MCPG}(D C G I V$ $+M C P G$ ). Data from six Purkinje cells. ${ }^{*} p<0.01$; NS; $p>0.05$ (paired $t$ test). E, Averaged time courses of DSI in the control (open symbols) and after bath-application of $3 \mathrm{~mm} \mathrm{MCPG} \mathrm{(closed} \mathrm{symbols).} \mathrm{Data} \mathrm{from} \mathrm{six}$ Purkinje cells.
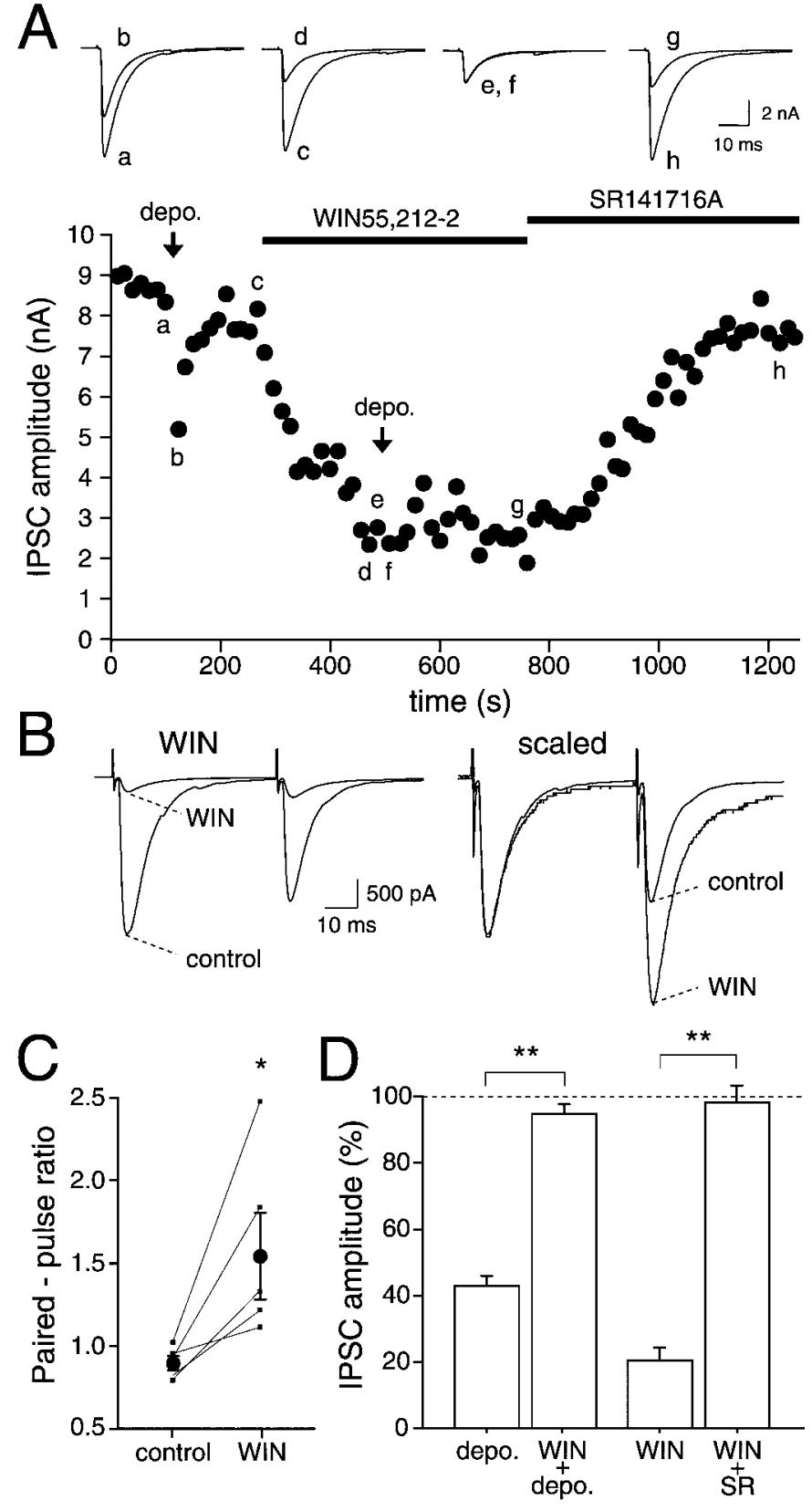

Figure 3. A cannabinoid agonist, W IN55,212-2, completely occludes DSI. $A$, Bath-applied WIN55,212-2 $(5 \mu \mathrm{M})$ induces a strong suppression of evoked IPSCs, which completely occludes DSI. A selective CB1 receptor antagonist, SR141716A $(1 \mu \mathrm{M})$, reverses the effect of WIN55,212-2. $B$, Bath-applied WIN55,212-2 (5 $\mu \mathrm{M})$ induces a clear increase in the paired-pulse ratio of evoked IPSCs. $C$, Changes in paired-pulse ratio induced by WIN55,212-2 $(5 \mu \mathrm{M})$ for individual Purkinje cells $\left(n=5 ;{ }^{*} p<0.05\right.$; paired $t$ test $)$. $D$, Summary bar graph for the changes in IPSC amplitudes induced by the depolarizing pulse train (depo.), the depolarizing pulse train plus $5 \mu \mathrm{M}$ WIN55,212-2 $(W I N+$ depo. $), 5 \mu \mathrm{M}$ WIN55,212-2 (WIN), and $5 \mu \mathrm{M}$ WIN55,212-2 in the presence of $1 \mu \mathrm{M}$ SR141716A $(W I N+S R)$. Data from six Purkinje cells. ${ }^{*} p<0.05 ;{ }^{* *} p<0.01$ (paired $t$ test).

more, we verified that the inhibitory synapses of the CB1 knockout mouse had no cannabinoid sensitivity because WIN55,212-2 $(5 \mu \mathrm{M})$ had no effect on IPSCs (Fig. 5D,E). These results indicate that DSI is mediated by endocannabinoids that act on presynaptic CB1 receptors. 


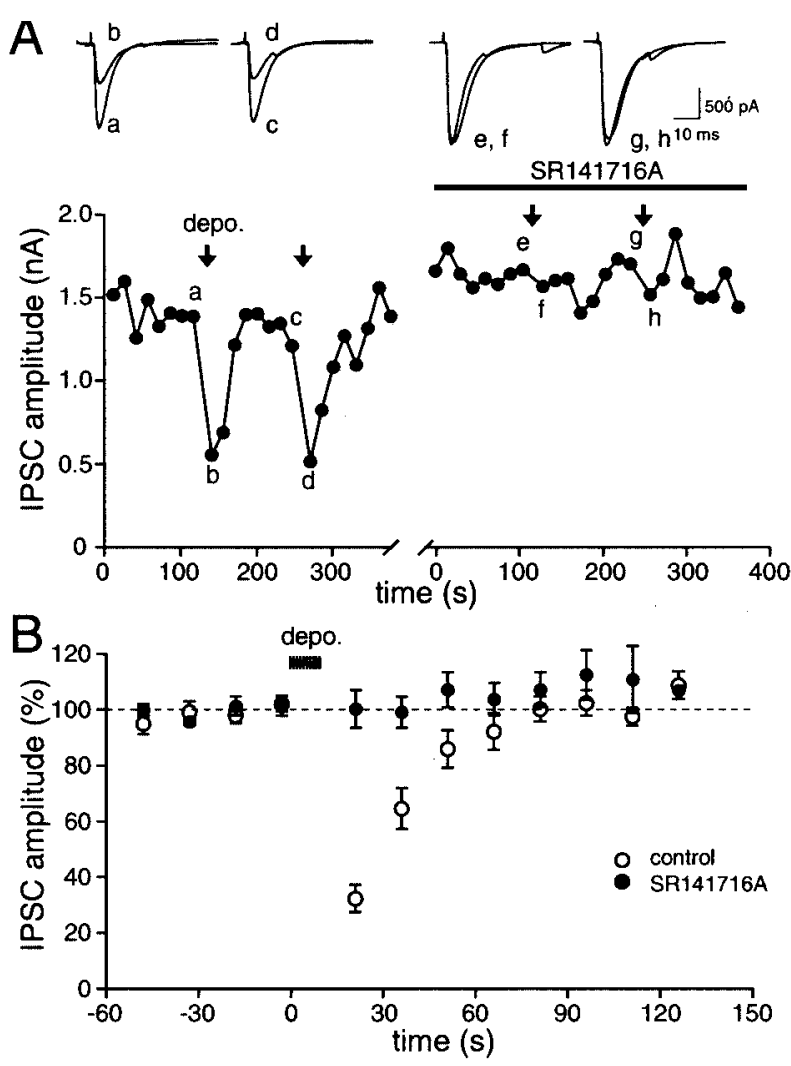

Figure 4. SR141716A totally eliminates DSI. A, Repeated application of the depolarizing pulse train at the times indicated by arrows (depo.) induces typical DSI with similar amplitudes in a Purkinje cell. After perfusion of SR141716A $(1 \mu \mathrm{M})$-containing external solution, application of the same pulse train causes no change in IPSCs. $B$, Averaged time courses of DSI in the control (open symbols) and after bath-application of $1 \mu \mathrm{M}$ SR141716A (closed symbols). Data from six Purkinje cells.

\section{Neither SR141716A nor genetic deletion of CB1 receptors affect depolarization-induced $\mathrm{Ca}^{2+}$ transients}

The data presented so far indicate that presynaptic CB1 receptors are essential for DSI. It is, however, still theoretically possible that SR141716A or genetic deletion of CB1 receptors reduced the elevation of intracellular $\mathrm{Ca}^{2+}$ concentration $\left(\left[\mathrm{Ca}^{2+}\right]_{\mathrm{i}}\right)$ of Purkinje cells during the depolarizing pulse train and thereby blocked the induction of DSI. To exclude this possibility, we examined whether the $\mathrm{Ca}^{2+}$ transients by the depolarizing pulse train are affected by SR141716A. We recorded from Purkinje cells with an internal solution containing a low affinity $\mathrm{Ca}^{2+}$ indicator (Magnesium Green; $500 \mu \mathrm{M}$ ) and measured the $\mathrm{Ca}^{2+}$ transients at the Purkinje cell somata (Eilers et al., 1995) as indicated in Figure $6 A$. The depolarizing pulse train induced DSI of evoked IPSCs (Fig. $6 B$ ) and transient elevation of $\left[\mathrm{Ca}^{2+}\right]_{i}$ at the soma (Fig. 6D). After perfusion of SR141716A, DSI was eliminated (Fig. 6C), whereas the $\mathrm{Ca}^{2+}$ transients remained unchanged (Fig. 6E). The summary data show that SR141716A blocked DSI (the DSI amplitudes are $57.2 \pm 3.1 \%$ in normal saline and $86.6 \pm 4.2 \%$ in SR141716A; $n=5 ; p<0.01 ; t$ test) but had no effect on the peak $\mathrm{Ca}^{2+}$ transients induced by the depolarizing pulse train (the $\Delta F / F_{0}$ values are $104.9 \pm 4.2$ in normal saline and $96.5 \pm 3.8$ in SR141716A; $n=6 ; p>0.05 ; t$ test). Furthermore, we confirmed that the depolarization-induced $\mathrm{Ca}^{2+}$ transients are intact in the CB1 knock-out mouse. The
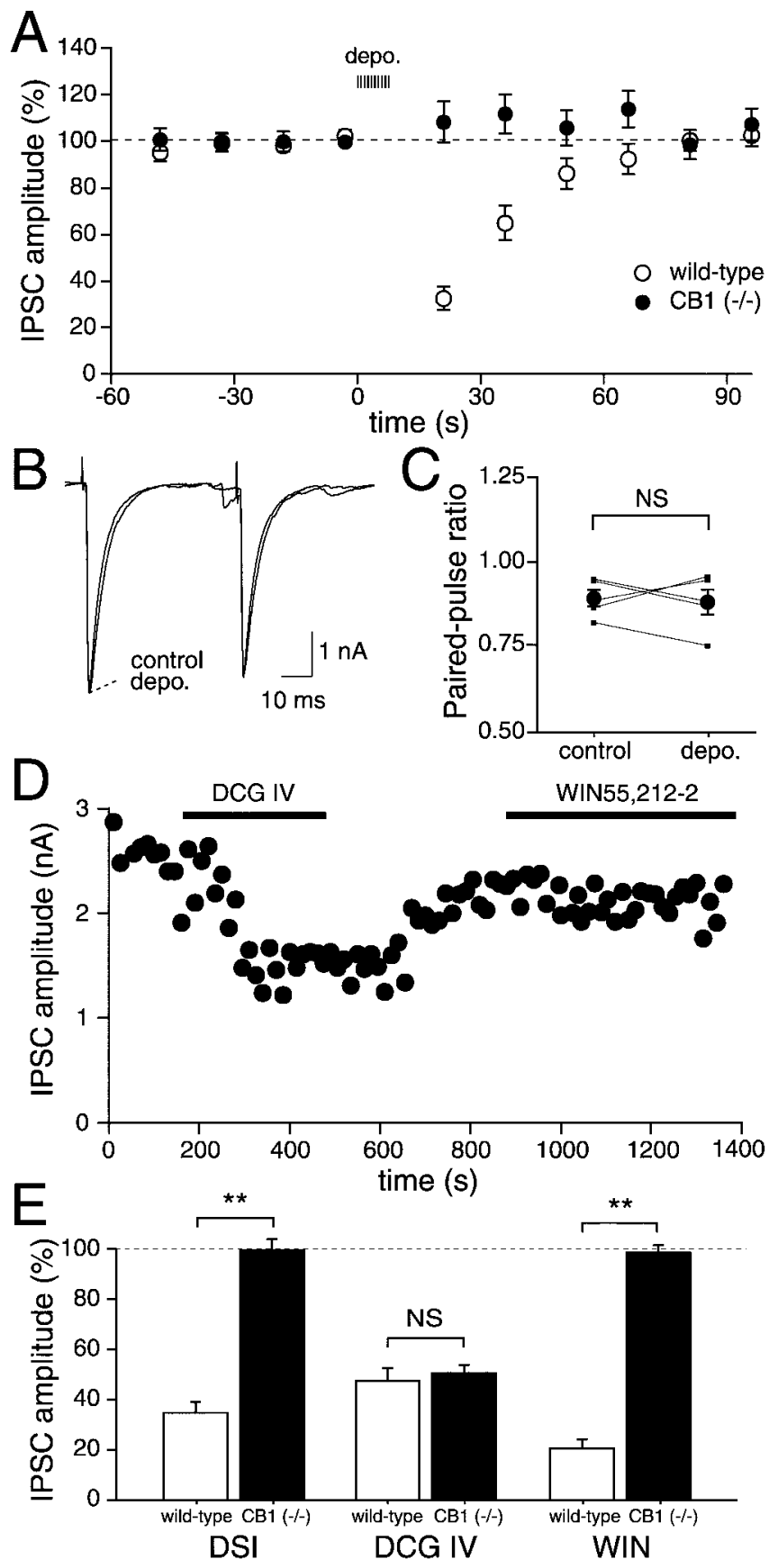

Figure 5. DSI is deficient in the CB1 receptor knock-out mouse. $A$, Averaged time courses of DSI in the wild-type (open symbols, $n=7$; the same data illustrated in Fig. $1 E$ ) and CB1 knock-out (closed symbols, $n=$ $5)$ mice. $B$, Example of IPSC traces (average of five consecutive responses) in response to paired stimuli (50 msec interval) from a CB1 knock-out mouse recorded before (control) and after (depo.) the depolarizing pulse train. $C$, Changes in paired-pulse ratio induced by the depolarizing pulse train for individual Purkinje cells from CB1 knock-out mice $(n=5$; NS $>$ 0.05; paired $t$ test). $D$, Time course of the change in IPSC amplitudes from a representative CB1 knock-out Purkinje cell. Bath-applied DCG IV (0.3 $\mu \mathrm{M})$ induces a suppression of evoked IPSCs, whereas WIN55,212-2 (5 $\mu \mathrm{M})$ had no effect. $E$, Summary bar graph for the changes in IPSC amplitudes induced by the depolarizing pulse train ( $D S I), 0.3 \mu \mathrm{M}$ DCG IV $(D C G I V)$, and $5 \mu \mathrm{M}$ WIN55,212-2 (WIN) for the wild-type (open columns) and CB1 knock-out ( filled columns) mice. The data for wild-type mice and are the same illustrated in Figure $2 D(D S I$ and $D C G I V)$ and 3D $(W I N)$. Data from 6 wild-type and five CB1 knock-out Purkinje cells. ${ }^{* *} p<0.01$; NS; $p>0.05$ ( $t$ test). 

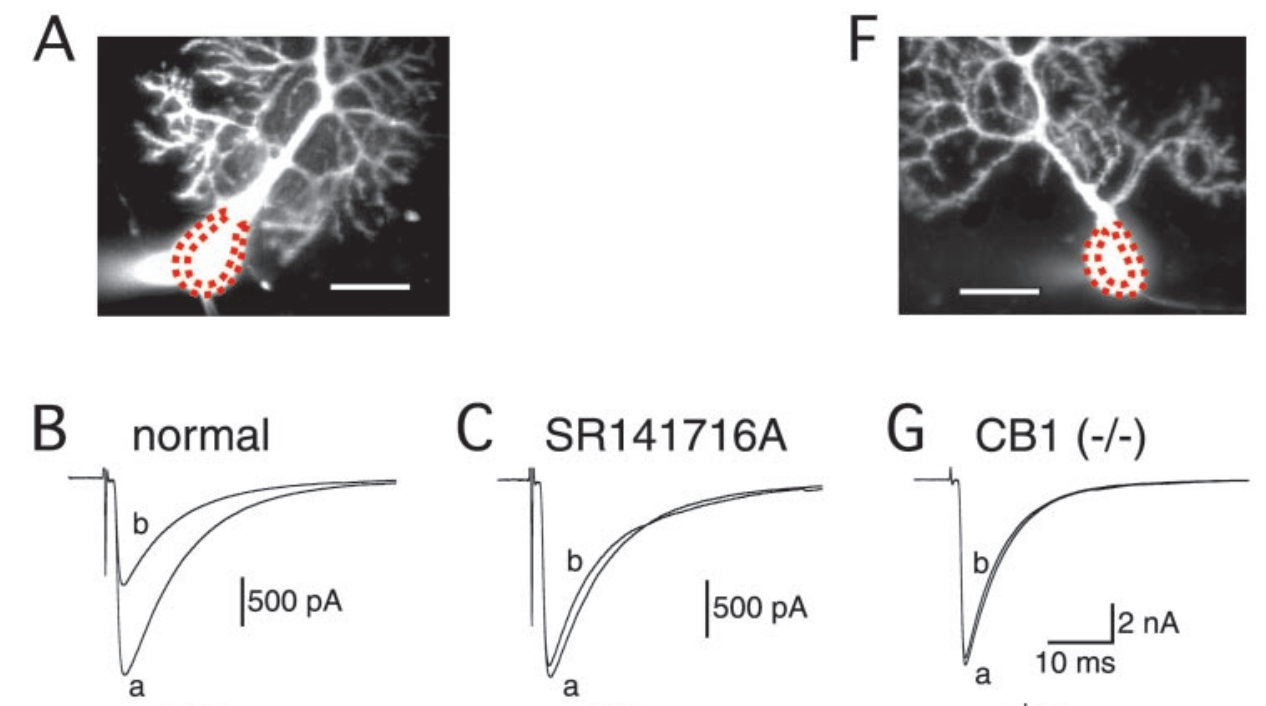

Figure 6. Neither SR141716A nor genetic deletion of CB1 receptors affect depolarization-induced $\mathrm{Ca}^{2+}$ transients. $A, F, \mathrm{Re}-$ constructed images of Purkinje cells from a wild-type mouse $(A)$ and a CB1 knock-out mouse $(F)$. The area depicted with dotted red line in each image indicates the somatic submembrane shell [Eilers et al., 1995 from which the $\mathrm{Ca}^{2+}$ signals shown in $D$ and $E$ (for $A$ ) or in $H$ (for $F$ )] are measured. Scale bars, $20 \mu \mathrm{m}$. $B, C, G$, Sample traces of IPSCs and time course of the change in IPSC amplitude caused by the depolarizing pulse train (depo.) for the wild-type Purkinje cell shown in $A$ (for $B, C$ ) and for the CB1 knock-out Purkinje cell shown in $F$ (for $G$ ). Records were obtained in normal external solution $(B, G)$ and after bath application of SR141716A (1 $\mu \mathrm{M})(C) . D, E$, $H, \mathrm{Ca}^{2+}$ signals from the regions depicted in $A$ (for $D, E$ ) and in $F$ (for $H$ ) obtained in normal external solution $(D, H)$ and after bath application of $S R 141716 A(1 \mu \mathrm{M})(E)$. The periods during which the $\mathrm{Ca}^{2+}$ signals by the depolarizing pulse train (depo.) are measured are depicted with horizontal bars

depolarizing pulse train induced no DSI (Fig. $6 G$ ) but elicited transient elevation of $\left[\mathrm{Ca}^{2+}\right]_{\mathrm{i}}$ (Fig. $6 \mathrm{H}$ ) measured at the soma (Fig. $6 F$ ). The summary data from nine Purkinje cells of CB1 knock-out mice shows no DSI $(89.4 \pm 4.0 \% ; n=9 ; p<0.01$; compared with the wild-type; $t$ test) and intact depolarizationinduced $\mathrm{Ca}^{2+}$ transients $\left(\Delta F / F_{0} ; 95.9 \pm 5.6 ; n=9 ; p>0.05\right.$; compared with the wild-type; $t$ test). These results lead us to conclude that DSI in the mouse cerebellum is mediated by endocannabinoids that are released from depolarized Purkinje cells and act retrogradely on CB1 receptors at inhibitory presynaptic terminals.

\section{DISCUSSION}

We report that DSI can readily be induced in IPSCs evoked by stimulating putative basket cell axons in mouse cerebellar Purkinje cells. Although a group II mGluR-specific agonist, DCG IV, caused a reversible presynaptic suppression of IPSCs, DCG IV with a saturating dose $(0.3 \mu \mathrm{M})$ did not completely occlude DSI. A mGluR antagonist, MCPG (3 mM), completely blocked the presynaptic effect of DCG IV, whereas it had no effect on DSI. These results clearly indicate that group II mGluRs on inhibitory presynaptic fibers do not play a major role in DSI. On the other hand, a cannabinoid receptor agonist, WIN55,212-2 (5 $\mu \mathrm{M})$, caused a presynaptic suppression of IPSCs and completely occluded DSI. A CB1-specific cannabinoid antagonist, SR141716A $(1 \mu \mathrm{M})$, totally abolished DSI. Furthermore, DSI was deficient in

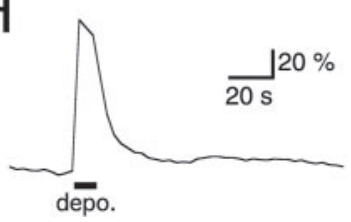

in $B, C$, and $G$. the cerebellum of the $\mathrm{CB} 1$ receptor knock-out mouse. These results clearly indicate that DSI in the mouse cerebellum is mediated by endocannabinoids that are released from depolarized Purkinje cells and act retrogradely on CB1 receptors at inhibitory presynaptic terminals.

\section{Glutamate is not a major mediator of DSI}

In slices from the cerebellum and hippocampus, it was considered previously that DSI is mediated by glutamate or a glutamate-like substance (Glitsch et al., 1996; Morishita et al., 1998). In Purkinje cells of the rat cerebellum, DSI of spontaneous IPSCs was reduced when the GABA release was inhibited by saturating doses of DCG IV (Glitsch et al., 1996). Both DSI and DCG IV-induced inhibition of miniature IPSC were inhibited by L-AP-3, which has complex effects on several ionotropic and metabotropic glutamate receptors. However, neither DSI nor DCG IV-induced inhibition was blocked by MCPG, a widely used mGluR antagonist that specifically blocks both group I and II mGluRs. From these results, Glitsch et al. (1996) propose that glutamate or a glutamate-like substance is released from depolarized rat Purkinje cells and acts on an unusual type of group II mGluR on inhibitory presynaptic fibers that is sensitive to DCG IV but totally insensitive to MCPG (Glitsch et al., 1996, 2000). In contrast, we have demonstrated in mouse Purkinje cells that DCG IV-induced presynaptic inhibition was almost completely blocked by MCPG (3 mM), whereas DSI was totally insensitive to the 
same dose of MCPG. Our results indicate that mouse inhibitory presynaptic fibers have a usual type of group II mGluR that is sensitive to DCG IV and is blocked by MCPG. The group II mGluR does not play a major role in DSI in mouse Purkinje cells. The reasons for the discrepancy between the results of Glitsch et al. (1996) and ours are not clear. They showed that L-AP-3 acted both as an antagonist and as a partial agonist of the group II mGluR in the rat (Glitsch et al., 1996). L-AP-3 reduced the basal miniature IPSC frequency by $\sim 28 \%$. They report that DSI was reduced by L-AP-3 from $51.3 \pm 2.6 \%$ in the control to $30.0 \pm$ $4.0 \%$. Therefore, the reduction of DSI may reflect the partial occlusion of DSI by the inhibition of GABA release caused by the agonistic action of L-AP-3 on group II mGluRs. They reported that MCPG (1 mM) failed to inhibit the effects of DCG IV. However, they used relatively high doses $(1-5 \mu \mathrm{M})$ of DCG IV, which is $\sim 10$ times higher than the saturating dose of DCG IV $(0.3 \mu \mathrm{M})$ for mouse Purkinje cells. Because MCPG is a competitive mGluR antagonist, its effect must be critically dependent on the agonist concentration. In fact, we observed that MCPG had only a weak antagonistic action against higher doses of DCG IV. Taken together, we conclude that glutamate or glutamate-like substance is not a major mediator of DSI in cerebellar Purkinje cells. Glitsch and Jack (2001) recently reported that DSI is reduced only slightly by LY-341495, a highly specific and potent antagonist of group II mGluR. They now conclude that activation of group II mGluRs play a relatively minor role in the induction of cerebellar DSI.

We have reported recently that activation of postsynaptic mGluR1 in Purkinje cells causes reversible suppression of excitatory transmitter release from presynaptic terminals that is mediated by CB1 receptors (Maejima et al., 2001b). This indicates that endocannabinoids are released from Purkinje cells in response to activation of postsynaptic mGluR1. The mGluR1dependent mechanism may work in a synergistic manner with the $\mathrm{Ca}^{2+}$-dependent pathway for the release of endocannabinoids from Purkinje cells. The depolarization-induced release of endocannabinoids may be enhanced when postsynaptic mGluR1dependent mechanism is active. It is, therefore, possible that the amplitude of DSI is influenced by the ambient glutamate concentration around Purkinje cells.

\section{Endocannabinoids mediate retrograde modulation of synaptic transmission}

It is recently revealed that endocannabinoids mediate the retrograde signal of DSI in the hippocampus (Ohno-Shosaku et al., 2001; Wilson and Nicoll, 2001). In cultured hippocampal neurons, the cannabinoid receptor agonist WIN55,212-2 mimics DSI and cannabinoid receptor antagonists, AM 281 and SR141716A completely eliminated DSI (Ohno-Shosaku et al., 2001). Wilson and Nicoll reported essentially the same results in the hippocampal slice (Wilson and Nicoll, 2001). In addition, they found that DSI is completely occluded by the pretreatment of the slices with WIN55,212-2 (Wilson and Nicoll, 2001). Very recently, Kreitzer and Regehr (2001b) reported that DSI of spontaneous IPSCs in the rat cerebellum is not mediated by activation of mGluRs or $\mathrm{GABA}_{\mathrm{B}}$ receptors but involves cannabinoid receptors. Furthermore, DSI was absent in the hippocampus of the CB1 receptor knock-out mouse (Wilson et al., 2001). Taken together with the results from the present study, the experimental evidence clearly indicates that endocannabinoids mediate retrograde signal for DSI in the hippocampus and cerebellum.

Kreitzer and Regehr (2001a) reported that depolarization- induced presynaptic suppression also occurs in excitatory climbing fiber and parallel fiber synapses onto cerebellar Purkinje cells. This phenomenon, termed depolarization-induced suppression of excitation (DSE), was abolished by a CB1 receptor antagonist, AM 251, and was occluded by the pretreatment of the slices with WIN55,212-2 (Kreitzer and Regehr, 2001a). Thus, both DSI and DSE appear to be mediated by endocannabinoids and have mechanisms in common. Postsynaptic depolarization triggers $\mathrm{Ca}^{2+}$ influx through voltage-gated $\mathrm{Ca}^{2+}$ channels and causes a transient increase in $\left[\mathrm{Ca}^{2+}\right]_{\mathrm{i}}$. The $\left[\mathrm{Ca}^{2+}\right]_{\mathrm{i}}$ increase will stimulate the biosynthesis of endocannabinoids and cause their release from the depolarized Purkinje cell. In support of this notion, previous biochemical data indicate that the two candidate endocannabinoids, anandamide and 2-arachidonylglycerol (2-AG), are produced and released from neurons in a $\mathrm{Ca}^{2+}$-dependent manner (Di Marzo et al., 1994; Bisogno et al., 1997; Stella et al., 1997). Then, the released endocannabinoids will diffuse the synaptic cleft retrogradely and bind to the CB1 on the inhibitory or excitatory presynaptic terminals contacting onto the depolarized Purkinje cell. The presence of CB1 receptors on inhibitory and excitatory presynaptic fibers in the cerebellum has been verified by immunohistochemical methods (Egertova and Elphick, 2000). Finally, the activation of presynaptic CB1 receptors will suppress the release of GABA or glutamate, presumably by inhibiting voltage-gated $\mathrm{Ca}^{2+}$ channels, as shown in neuroblastoma-glioma cells (Mackie and Hille, 1992) and hippocampal neurons (Twitchell et al., 1997; Hoffman and Lupica, 2000). Takahashi and Linden (2000) reported that W IN55,212-2 suppresses the frequency of miniature IPSCs in Purkinje cells. One possibility would be that activation of presynaptic CB1 receptors directly interferes with the release machinery of GABA containing synaptic vesicles. It is reported that DSI is observed in miniature IPSCs in cerebellar Purkinje cells (Llano et al., 1991; Glitsch et al., 1996; Glitsch and Jack, 2001). These results suggest that endocannabinoids may exert some additional effects on inhibitory presynaptic terminals of the cerebellum to cause DSI.

Recent studies have clarified that endocannabinoid release is triggered by an elevation of $\left[\mathrm{Ca}^{2+}\right]_{\mathrm{i}}$ (Kreitzer and Regehr, 2001a; Ohno-Shosaku et al., 2001; Wilson and Nicoll, 2001) or activation of mGluR1 (Maejima et al., 2001b) in postsynaptic neurons. The elevation of $\left[\mathrm{Ca}^{2+}\right]_{i}$ is caused by the activation of postsynaptic receptors and channels and reflects the activity of postsynaptic neurons. Activation of mGluR1 in Purkinje cells requires repetitive activation of parallel fibers (Batchelor and Garthwaite, 1997; Finch and Augustine, 1998; Takechi et al., 1998), which also reflects the activity of postsynaptic neurons. Presynaptic terminals can sense the postsynaptic activity by detecting released endocannabinoids from postsynaptic neurons with the CB1. Because the CB1 is abundantly expressed in various regions of CNS (Herkenham et al., 1990; Herkenham et al., 1991; Matsuda et al., 1993; Egertova and Elphick, 2000), it is likely that the retrograde modulation mediated by endocannabinoids is a general and important mechanism by which the postsynaptic activity can influence the presynaptic function.

\section{REFERENCES}

Batchelor AM, Garthwaite J (1997) Frequency detection and temporally-dispersed synaptic signal association through a metabotropic glutamate receptor pathway. Nature 385:74-77.

Bisogno T, Sepe N, Melck D, Maurelli S, De-Petrocellis L, Di Marzo V (1997) Biosynthesis, release and degradation of the novel endogenous cannabimimetic metabolite 2-arachidonoylgrycerol in mouse neuroblastome cells. Biochem J 322:671-677.

Di Marzo V, Fontana A, Cadas H, Schinelli S, Cimino G, Schwartz J-C, 
Piomelli D (1994) Formation and inactivation of endogenous cannabinoid anandamide in central neurons. Nature 372:686-691.

Egertova M, Elphick MR (2000) Localisation of cannabinoid receptors in the rat brain using antibodies to the intracellular C-terminal tail of CB1. J Comp Neurol 422:159-171.

Eilers J, Callewaert G, Armstrong CM, Konnerth A (1995) Calcium signaling in a narrow somatic submembrane shell during synaptic activity in cerebellar Purkinje neurons. Proc Natl Acad Sci USA 92:10272-10276.

Finch EA, Augustine GJ (1998) Local calcium signalling by inositol1,4,5-trisphosphate in Purkinje cell dendrites. Nature 396:753-756.

Glitsch M, Jack JJB (2001) Evidence that glutamate acting on presynaptic type-II metabotropic glutamate receptors alone does not fully account for the phenomenon of depolarization-induced suppression of inhibition in cerebellar Purkinje cells. Pflügers Arch 442:404-408.

Glitsch M, Llano I, Marty A (1996) Glutamate as a candidate retrograde messenger at interneurone-Purkinje cell synapses of rat cerebellum. J Physiol (Lond) 497:531-537.

Glitsch M, Llano I, Marty A (2000) The retrograde inhibition of IPSCs in rat cerebellar Purkinje cells is highly sensitive to intracellular $\mathrm{Ca}^{2+}$. Eur J Neurosci 12:987-993.

Herkenham M, Lynn AB, Little MD, Johnson MR, Melvin LS, De Costa BR, Rice KC (1990) Cannabinoid receptor localization in brain. Proc Natl Acad Sci USA 87:1932-1936.

Herkenham M, Lynn AB, Johnson MR, Melvin LS, de Costa BR, Rice KC (1991) Characterization and localization of cannabinoid receptors in rat brain: a quantitative in vitro autoradiographic study. J Neurosci 11:563-583.

Hoffman AF, Lupica CR (2000) Mechanisms of cannabinoid inhibition of $\mathrm{GABA}_{\mathrm{A}}$ synaptic transmission in the hippocampus. J Neurosci 20:2470-2479.

Kano M, Rexhausen U, Dreessen J, Konnerth A (1992) Synaptic excitation produces a long-lasting rebound potentiation of inhibitory synaptic currents in cerebellar Purkinje cells. Nature 356:601-604.

Kano M, Hashimoto K, Chen C, Abeliovich A, Aiba A, Kurihara H, Watanabe M, Inoue Y, Tonegawa S (1995) Impaired synapse elimination during cerebellar development in $\mathrm{PKC} \gamma$ mutant mice. Cell 83:1223-1231.

Kano M, Hashimoto K, Kurihara H, Watanabe M, Inoue Y, Aiba A, Tonegawa S (1997) Persistent multiple climbing fiber innervation of cerebellar Purkinje cells in mice lacking mGluR1. Neuron 18:71-79.

Kreitzer AC, Regehr WG (2001a) Retrograde inhibition of presynaptic calcium influx by endogenous cannabinoids at excitatory synapses onto Purkinje cells. Neuron 29:717-727.

Kreitzer AC, Regehr WG (2001b) Cerebellar depolarization-induced suppression of inhibition is mediated by endogenous cannabinoids. J Neurosci 21:RC174.

Llano I, Leresche N, Marty A (1991) Calcium entry increases the sensitivity of cerebellar Purkinje cells to applied GABA and decreases inhibitory synaptic currents. Neuron 6:565-574.
Mackie K, Hille B (1992) Cannabinoids inhibit N-type calcium channels in neuroblastoma-glioma cells. Proc Natl Acad Sci USA 89:3825-3829.

Maejima T, Ohno-Shosaku T, Kano M (2001a) Endogenous cannabinoid as a retrograde messenger from depolarized postsynaptic neurons to presynaptic terminals. Neurosci Res 40:205-210.

Maejima T, Hashimoto K, Yoshida T, Aiba A, Kano M (2001b) Presynaptic inhibition caused by retrograde signal from metabotropic glutamate to cannabinoid receptors. Neuron 31:463-475.

Matsuda LA, Lolait SJ, Brownstein MJ, Young AC, Bonner TI (1990) Structure of a cannabinoid receptor and functional expression of the cloned cDNA. Nature 346:561-564.

Matsuda LA, Bonner TI, Lolait SJ (1993) Localization of cannabinoid receptor mRNA in rat brain. J Comp Neurol 327:535-550.

Montgomery J, Madison DV (2001) The grass roots of synapse suppression. Neuron 29:567-570.

Morishita W, Kirov SA, Alger BE (1998) Evidence for metabotropic glutamate receptor activation in the induction of depolarizationinduced suppression of inhibition in hippocampal CA1. J Neurosci 18:4870-4882.

Munro S, Thomas KL, Abu-Shaar M (1993) Molecular characterization of a peripheral receptor for cannabinoids. Nature 365:61-65.

Ohno-Shosaku T, Sawada S, Yamamoto C (1998) Properties of depolarization-induced suppression of inhibitory transmission in cultured rat hippocampal neurons. Pflügers Arch 435:273-279.

Ohno-Shosaku T, Maejima T, Kano M (2001) Endogenous cannabinoids mediate retrograde signals from depolarized postsynaptic neurons to presynaptic terminals. Neuron 29:729-738.

Pitler TA, Alger BE (1992) Postsynaptic spike firing reduces synaptic $\mathrm{GABA}_{\mathrm{A}}$ responses in hippocampal pyramidal cells. J Neurosci 12:4122-4132.

Stella N, Schweitzer P, Piomelli D (1997) A second endogenous cannabinoid that modulates long-term potentiation. Nature 388:773-778.

Takahashi KA, Linden DJ (2000) Cannabinoid receptor modulation of synapses received by cerebellar Purkinje cells. J Neurophysiol 83:1167-1180.

Takechi H, Eilers J, Konnerth A (1998) A new class of synaptic response involving calcium release in dendritic spines. Nature 396:757-760.

Twitchell W, Brown S, Mackie K (1997) Cannabinoids inhibit N- and $\mathrm{P} / \mathrm{Q}$-type calcium channels in cultured rat hippocampal neurons. J Neurophysiol 78:43-50.

Vincent P, Armstrong CM, Marty A (1992) Inhibitory synaptic currents in rat cerebellar Purkinje cells: modulation by postsynaptic depolarization. J Physiol (Lond) 456:453-471.

Wilson RI, Nicoll RA (2001) Endogenous cannabinoids mediate retrograde signalling at hippocampal synapses. Nature 410:588-592.

Wilson RI, Kunos G, Nicoll RA (2001) Presynaptic specificity of endocannabinoid signaling in the hippocampus. Neuron 31:453-462.

Zimmer A, Zimmer AM, Hohmann AG, Herkenham M, Bonner TM (1999) Increased mortality, hypoactivity, and hypoalgesia in cannabinoid CB1 receptor knockout mice. Proc Natl Acad Sci USA 96:57805785 . 